\title{
Review
}

\section{Vascular factors in diabetic neuropathy}

\author{
S. Tesfaye ${ }^{1}$, R.Malik ${ }^{2}$, J.D. Ward $^{3}$ \\ ${ }^{1}$ Diabetes Unit, Walton Hospital, Walton, Liverpool, UK \\ ${ }^{2}$ Department of Medicine, Manchester Royal Infirmary, Manchester, UK \\ ${ }^{3}$ Diabetes Research Unit, Royal Hallamshire Hospital, Sheffield, UK
}

Summary Despite considerable research we still do not have a comprehensive explanation for the pathogenesis of diabetic neuropathy. Although chronic hyperglycaemia is almost certainly involved, it is not known whether the primary pathology is metabolic, microvascular, or an interaction between the two. Hyperglycaemia-induced polyol pathway hyperactivity associated with nerve sorbitol accumulation and myo-inositol depletion may play a part in the genesis of diabetic neuropathy. The case for microvascular disease in diabetic neuropathy is now strong. Fibre loss in human sural nerve is multifocal, suggesting ischaemia. The degree of vessel disease has been related to the severity of neuropathy. People with chronic obstructive pulmonary disease develop the so called "hypoxic neuropathy" in which similar microvascular changes occur as in diabetic neuropathy. In rats with experimental diabetic neuropathy nerve blood flow is reduced and oxygen supplementation or vasodilator treatment improved the deterioration in conduction velocity and nerve blood flow. Similarly, in human diabetic neuropathy, there is impaired nerve blood flow, epineurial arterio-venous shunting and a reduction in sural nerve oxygen tension. At what stage during the development of nerve damage these changes occur is yet to be determined. [Diabetologia (1994) 37: 847-854]

Key words Diabetic neuropathy, microangiopathy, nerve, hypoxia, blood flow.
Diabetic polyneuropathy commonly leads to considerable morbidity and mortality [1]. The most common neuropathic syndrome associated with diabetes is the distal symmetric, predominantly sensory variety, which is the major initiatng factor for foot ulceration and infection [2]. Neuropathic pain is often disabling, leading to considerable distress and loss of sleep [3-5]. Conventional treatment is largely symptomatic and frequently ineffective. Yet, the aetiology of this common condition and the mechanisms of neuropathic pain remain obscure [6-8]. Moreover, we have no reliable means by which we can predict the development, or indeed prevent the progression of clinical diabetic neuropathy [9]. These deficien-

Corresponding author: Dr. S. Tesfaye, Department of Diabetic Medicine, Walton Hospital, Rice Lane, Walton, Liverpool L9 $1 \mathrm{AE}, \mathrm{UK}$

Abbreviations: RICF, resistance to ischaemic conduction failure. cies emphasise the need to pursue the cause of this unpleasant complication. Although there is now a substantial body of evidence for the involvement of chronic hyperglycaemia [10-16], it is not known whether metabolic abnormalities directly cause nerve damage (Table 1 ) or whether they do so by first causing an alteration in nerve microvasculature. In this review we highlight the role of vascular factors in the pathogenesis of diabetic neuropathy (Fig. 1).

\section{Microangiopathy in human diabetic neuropathy}

The view that vascular disease may play a part in the pathogenesis of diabetic neuropathy is not recent. In 1893, Price [17] described areas of nerve degeneration in the posterior tibial nerve trunks supplied by severely atheromatous posterior tibial arteries with occlusion of smaller microscopic vessels. Early this cen- 
Table 1. Some of the proposed metabolic alterations in the diabetic peripheral nerve

Sorbitol accumulation [96-98]

Myo-inositol depletion [99]

Reduction in sodium-potassium-ATPase $[100,101]$

Non-enzymatic glycosylation of proteins [21]

Defective protein synthesis [102]

Abnormalities of axonal flow [103]

Reduction in gamma-linolenic acid [55, 88, 89]

Abnormalities in transport and levels of nerve growth factor $[104,105]$

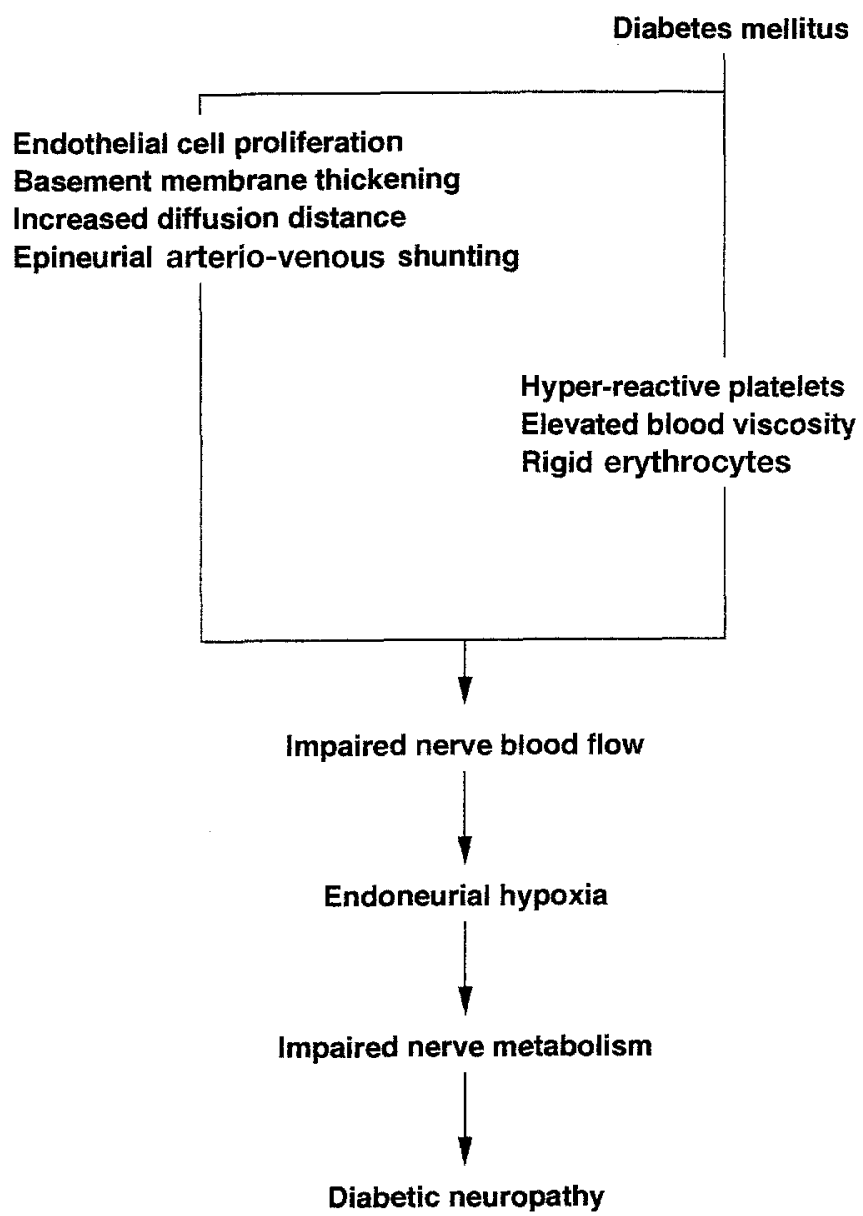

Fig. 1. Some of the proposed microvascular and haemorheological abnormalities leading to endoneurial hypoxia

tury, Woltman and Wilder [18] also attributed neuropathy to arteriosclerosis of the vasa nervorum. However, the first detailed study linking diabetic neuropathy to microvascular disease was untertaken by Fagerberg [19]. He demonstrated the presence of thickening and hyalinization of intraneural vessel wall by a material staining positive with periodic acid Schiff. These changes were later found to be due to reduplication of the capillary basal lamina [20], which may be the result of episodes of increased endothelial cell turnover or indeed due to non-enzymatic glycation [21].
Several studies have confirmed the presence of endoneurial microangiopathy in both mild and chronic diabetic neuropathy [22-27]. In a recent sural nerve morphometric study, endoneurial capillary basement membrane (Fig.2), endothelial cell profile number and total diffusion barrier were found to be significantly increased in diabetic neuropathy [27]. These changes were found to be more severe in endoneurial vessels compared to epineurial [27] muscle [25] or skin [25] capillaries, suggesting an intraneural neurovascular interaction. Furthermore, only the degree of endoneurial vessel disease was related to the severity of both nerve fibre pathology and clinical neuropathy [25], a relationship which has also been reported by other studies [26].

Endothelial cell hyperplasia has been found in endoneurial capillaries in diabetic neuropathy [28], in some cases leading to complete occlusion of small vessels (Fig. 3) [29]. Timperly et al. [30] described plugging of small vessels by degenerate cellular material and electron-dense protein in diabetic patients with a predominantly motor neuropathy. Endoneurial capillary closure has also been shown in patients with diabetic neuropathy [31] and related to neuropathic severity. Furthermore, a recent morphometric study has demonstrated endothelial cell hypertrophy and hyperplasia resulting in a reduction in luminal size of transperineurial capillaries [32]. These changes, in addition to haemorheological abnormalities [33] may well lead to endoneurial hypoxia [34].

The symmetrical nature of distal, primarily sensory diabetic neuropathy has been used as evidence against the microvascular hypothesis of nerve damage. However, in an autopsy study of 16 diabetic neuropathic subjects, Johnson et al. [35] found focal fascicular lesions characterised by reduced density of myelinated axons within fascicles in the posterior tibial nerve and the lumbosacral trunk. These lesions were found to be identical to those found in biopsies of nerves of non-diabetic subjects with vasculitis. More recently, Beggs et al. [36] from the same unit have demonstrated that diabetic patients have a selective early loss of autonomic innervation in the transperineurial "sleeves" and exaggerated loss of innervation to the larger arterioles in the epineurium. They concluded that autonomic neuropathy of the vasa nervorum leading to impairment of circulatory autoregulation may cause nerve ischaemia. From post-mortem studies, Dyck et al. [37] also demonstrated that proximal multifocal lesions summate to produce diffuse fibre loss distally in diabetic patients with distal symmetric neuropathy. In another morphometric and teased fibre study of sural nerve biopsies, Dyck et al. [38] showed that fibre loss is multifocal in diabetic neuropathy, strongly implicating ischaemia as the primary cause.

Perhaps the most compelling evidence for the importance of vascular factors in the aetiology of dia- 


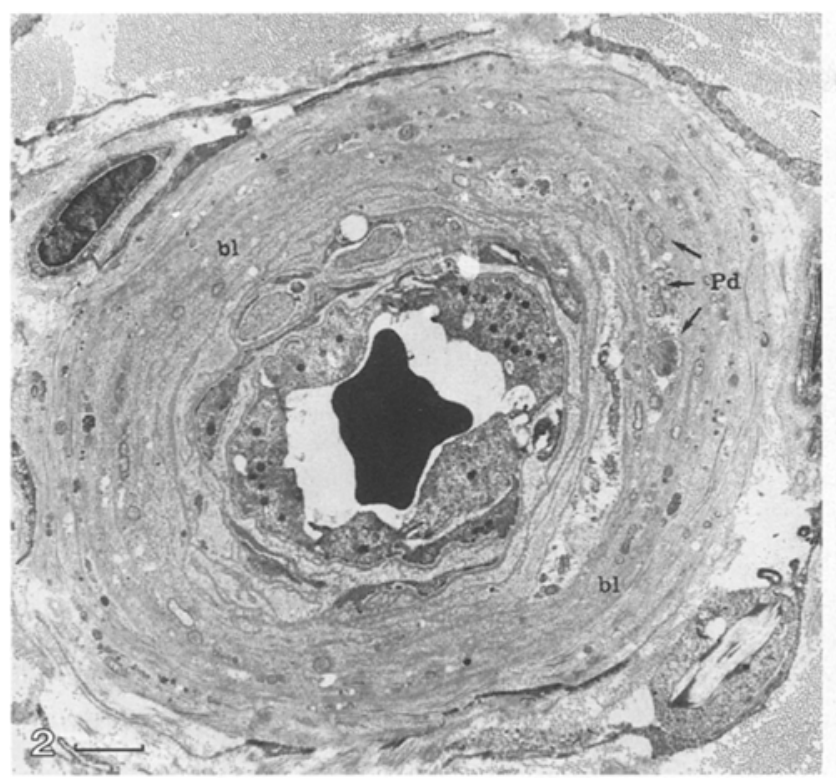

Fig. 2. Electronmicrograph of an endoneurial capillary from a patient with established neuropathy demonstrating gross thickening of basement membrane (bl), pericyte degeneration and pericyte debris (Pd) with endothelial cell hypertrophy and hyperplasia. (bar $=1 \mu \mathrm{m}$ )

Fig. 3. Lightmicrograph of a semithin transverse section of a fascicle from a sural nerve of a diabetic patient with established neuropathy demonstrating loss of myelinated fibres (mf), the presence of regenerative clusters (rc) and microangiopathy in the form of basement membrane thickening and luminal occlusion in endoneurial capillaries (cap). Magnification $\times 400$

betic neuropathy comes from focal neuropathies of acute onset such as third cranial nerve palsy [39] and mononeuritis multiplex [40] of diabetes. These studies have attributed the nerve lesions to ischaemia on the basis of their focal nature, their association with severe disease of small vessels, and the clinical patterns of onset and recovery. Despite these, however, there are few studies on the state of epineurial nutrient arteries in distal symmetric neuropathy. A study by Korthals et al. [41] showed that epineurial vessel intimal area and numbers of intimal nuclei were significantly greater in diabetic subjects, most of whom had neuropathy compared to healthy control subjects. They postulated that these lesions could result in nerve ischaemia although no direct relationship was found between the increase in intima and severity of nerve fibre degeneration.

\section{Experimental nerve ischaemia}

Peripheral nerve is supplied by a large network of longitudinal capillaries within the endoneurium and epineurial nutrient arterioles. Because of numerous

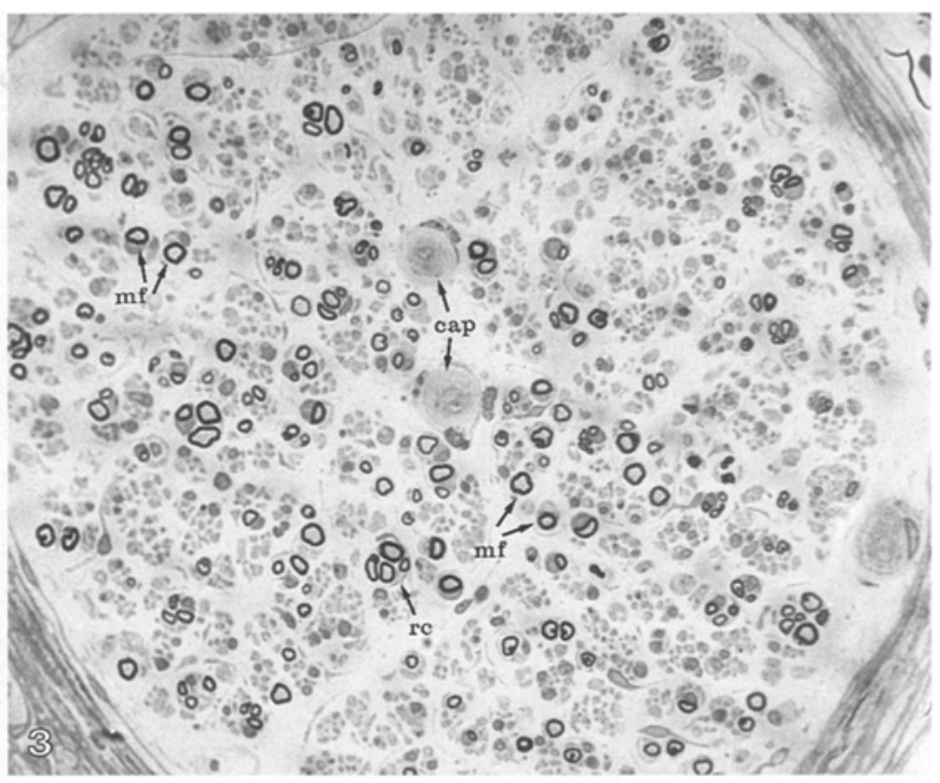

collateral anastomoses between these two vascular systems, ligation of a single nutrient artery or nutrient arteries of a small segment results in only a partial or patchy ischaemia [42]. This observation has been confirmed by other animal studies [43, 44]. Nukada and Dyck [44] injected microspheres into arteries supplying the sciatic nerve in order to selectively occlude endoneurial vessels, and observed that many microvessels had to be occluded before fibre degeneration resulted. Recently, the acute morphological effect of experimental ischaemia on the ultrastructural features of endoneurial microvessels has been studied in rats [45]. In ischaemic nerves there was an increase in basement membrane, and in the number of pericytes and endothelial cells that appeared swollen. Such studies offer indirect evidence for the importance of microvascular disease in the genesis of nerve damage in diabetes.

\section{Nerve blood flow and oxygen tension: studies in diabetic animals}

In recent years there have been a number of animal studies that further strengthen the case for microvascular/hypoxic mechanisms in the pathogenesis of diabetic neuropathy.

Hydrogen clearance method. Using a hydrogen clearance method, Tuck et al. [46] demonstrated that rats with experimental diabetic neuropathy have reduced nerve blood flow and oxygen tension. Cameron et al. [47] made the observation that a reduction in nerve blood flow of about $50 \%$ occurs as early as one week after the induction of diabetes and demonstrated that neuropathy could be prevented or corrected by vasodilator treatment $[48,49]$ that improves nerve blood flow. Oxygen supplementation [50] or 
hyperbaric oxygen rearing [51] has also been found to improve deterioration in nerve conduction velocity. Furthermore, in a hypoxic environment, normal rats develop electrophysiological [52] and morphological [53] abnormalities similar to those seen in experimental diabetes in the absence of hyperglycaemia. Central hypoxaemia also provokes neurological deficits similar to those seen in experimental diabetes [54].

Laser Doppler flowmetry. Laser Doppler velocimetry has been employed to measure nerve blood flow [55, 56]. In a recent study, sciatic nerve laser Doppler flux in rats with experimental diabetes was found to be $80 \%$ of that of controls after 4 days of induction of diabetes and steadily fell and formed a plateau at $40 \%$ of control values after 4 weeks [57]. Similar results were obtained in a previous study [56]. Treatment of diabetic rats with insulin prevented the reduction in nerve blood flow [57]. Nerve Doppler flux in $\mathrm{BB}$ rats with genetic diabetes of 6 weeks duration was also significantly reduced compared to non-diabetic $B B$ rats [57].

Injection of radiolabelled microspheres. Recent studies using an alternative method of measuring nerve blood flow by injection of radiolabelled microspheres, have shown an apparently contrary result of increased endoneurial and perineurial sciatic blood flow early after the onset of experimental diabetes [58]. Williamson et al. [59] formulated an hypothesis in which increased oxidation of sorbitol to fructose in vascular cells results in an increase in the cytosolic ratio of $\mathrm{NADH} / \mathrm{NAD}^{+}$. This increase in $\mathrm{NADH} /$ $\mathrm{NAD}^{+}$constitutes "pseudohypoxia" without a decrease in tissue $\mathrm{pO}_{2}$, the vascular response to which is vasodilatation and increased blood flow. This process is then postulated to eventually result in vascular sclerosis and impaired blood flow [59].

${ }^{14} \mathrm{C}$ butanol/tourniquet method. Monafo et al. [60] found that sciatic nerve blood flow was reduced in diabetic rats by using yet another method which involves intravenous injection of ${ }^{14} \mathrm{C}$ butanol.

As the animal models studied by the various groups are similar, the observed differences in nerve blood flow may only reflect methodological variations.

\section{Nerve oxygen tension and blood flow in human diabetic neuropathy}

In human diabetic neuropathy there is a reduction in sural nerve oxygen tension [34] but elevation of $\mathrm{PO}_{2}$ in foot veins due to arterio-venous shunting [61]. Although histological studies have shown that there are severe microvascular changes at the stage of clinical neuropathy, there have been no in vivo studies of nerve blood flow in man. By using novel in vivo techniques of sural nerve photography and fluorescein angiography, recent work has demonstrated the impairment of nerve blood flow and the presence of active epineurial arterio-venous shunts in human diabetic neuropathy [62]. There was wide-spread epineurial vessel abnormality with severe arteriolar attenuation and venous tortuosity and distension. It is not clear whether epineurial arterio-venous shunting [62] is a contributory factor or the result of nerve damage. However, the presence of epineurial arterio-venous shunts as well as a fine network of blood vessels resembling the "new vessels" of the retina in subjects with "insulin neuritis" [5], a transient neuropathy that follows rapid improvement in glycaemic control [63], supports the view that microvascular disease and arterio-venous shunting are causal rather than epiphenomenal factors in the genesis of diabetic neuropathy. An acute onset neuropathy 6 weeks after lowering of blood glucose levels might be expected to be due to metabolic derangement and yet at such an early stage we see such dramatic acute vascular changes [5]. It is well recognised that arterio-venous shunting is a feature of the diabetic neuropathic leg $[61,64,65]$ and it seems likely that the same mechanism takes place at the level of the nerve leading to nerve hypoxia. This would be consistent with the observation that nerve fibre degeneration is multifocal in diabetic neuropathy $[35,37,38]$. Loss of sympathetic fibres could result in arteriovenous shunting [36]. Following the demonstration of such shunting in the diabetic limb, similar Doppler sonogram abnormalities and venous oxygenation were found in the limbs of non-diabetic subjects with quadriplegia - total sympathetic denervation [66].

Recently, exercise-induced conduction velocity increment has been demonstrated to be markedly reduced in diabetic neuropathy [67]. This contrasts with the observation that nerve conduction increases by comparable amounts in both non-neuropathic diabetic and neuropathic diabetic subjects, on direct warming of a limb [67]. The impairment of exerciseinduced conduction velocity increment in diabetic neuropathy is not surprising as the epineurial vessels supplying the neuropathic nerve are severely diseased [62] and consequently nerve blood flow is unlikely to increase after exercise. Exercise-induced conduction velocity increment may therefore be regarded as a non-invasive measure of nerve blood flow.

\section{Haemorheological abnormalities}

Evidence for the presence of a hypercoagulable state in diabetes is strong. Several studies have suggested that haemorheological abnormalities may contribute to impaired blood flow brought about by microvascu- 
lar disease [68]. Fibrin deposition [30] and platelet clumping [69] have been observed in endoneurial vessels in diabetic neuropathy. Diabetic erythrocytes have been found to be less deformable than normal [70] and would therefore be expected to travel at a slower velocity in capillaries. This is compounded by increased erythrocyte aggregability and adhesiveness [71], abnormalities of platelet function, and increased blood and plasma viscosity $[72,73]$. According to Poiseuille's Law the rate of flow is proportional to the fourth power of the radius of a vessel. Thus, vessels of low flow such as capillaries are particularly susceptible to episodes of sludging and stasis which if severe, could result in tissue ischaemia. However, the exact causal relationship between haemorheological factors and diabetic complications is not yet clearly understood.

\section{Resistance to ischaemia}

An interesting characteristic of the diabetic nerve is what is termed "resistance to ischaemic conduction failure" (RICF). When blood supply is occluded, the diabetic nerve is able to maintain its function as measured by electrophysiological parameters for an abnormally longer period than a normal nerve [74]. This feature has been shown in newly-diagnosed diabetic patients and did not change with satisfactory glycaemic control [75]. When non-diabetic rats are reared in hypoxic conditions they develop RICF [76], and oxygen supplementation [50] or hyperbaric oxygenation [51] prevents the development of RICF in experimental diabetes. Although the cause remains controversial, a hypoxic mechanism has been forwarded, as RICF which was reversed with improvement of oxygenation was demonstrated in hypoxic subjects with chronic obstructive airways disease [77]. Indeed, people with chronic obstructive airways disease develop a peripheral neuropathy, first described by Appenzeller et al. [78], in which similar microvascular changes occur as in diabetic neuropathy $[79,80]$.

\section{Potential therapeutic approaches}

Recently, a number of pharmacological agents that increase nerve blood flow, such as the calcium antagonist nifedipine [81], the alpha adrenergic receptor blocker prazocin [48], the nicotinic acid derivative niceritrol [82], the angiotensin converting enzyme inhibitor lisinopril [49], and an angiotensin II receptor blocker [83] have been found to improve nerve function in experimental diabetes. Aminoguanidine, which prevents the generation of advanced glycation end-products has been postulated to prevent nerve ischaemia and improve nerve conduction in streptozotocin diabetes by an action in nerve microvessels [84]. Recently, glutathione, a free radical scavenger, has been found to be partially effective in the prevention of diabetic neuropathy in experimental diabetes [85] possibly acting by improving nerve hypoxia [86]. Another recent study has also shown that treatment with the anti-oxidant probucol prevented nerve conduction deficit, reductions in endoneurial blood flow and oxygen tension in streptozotocin diabetic rats [87]. Gamma linolenic acid therapy has also been found to improve neuropathic symptoms and measures of nerve function [88]. There is some evidence that these changes may be due to improvement in nerve blood flow [55,89].

In human diabetic neuropathy, a preliminary study by Reja et al. [90] has shown small but significant improvements in electrophysiological and quantitative sensory tests following 12 weeks of treatment with lisinopril. However, this has yet to be confirmed in large, controlled and double-blind trials. Recent observations of impaired nerve blood flow and the striking abnormalities of epineurial nutrient vessels in human diabetic neuropathy [62], would support that therapeutic measures must also be directed at improving nerve blood flow [91].

\section{Conclusion}

Studies in animal models and in patients with diabetic neuropathy have greatly enhanced our knowledge of diabetic neuropathy. There is little doubt of the presence of severe microvascular changes at the stage of clinical diabetic neuropathy but there is still a large gap in our knowledge of how these changes are initiated. A number of hypotheses including the formation of advanced glycation end products [21], increased oxygen free radical activity [92] and reduced endothelial nitric oxide activity $[93,94]$ have been forwarded linking chronic hyperglycaemia to microvascular damage. The strong association seen between retinopathy, nephropathy and neuropathy suggests a common pathogenetic mechanism in these complications. Multiple factors are likely to be implicated in the pathogenesis of diabetic polyneuropathy and although metabolic factors are likely to be the source of all diabetic complications, vascular/haemodynamic factors [95] that lead to impairment of function in the retina and the kidney, must now be considered to play an important role in the initiation or promotion of clinical diabetic neuropathy.

Acknowledgements. Mr. R. Hancock, Department of Medical Illustration, Walton Hospital, Liverpool. 


\section{References}

1. Ward JD, Goto Y (1990) Diabetic neuropathy. John Wiley and Sons, Chichester

2. Ward JD (1982) The diabetic leg. Diabetologia 22: 141147

3. Watkins PJ (1984) Pain and diabetic neuropathy. BMJ 288: 168-169

4. Archer AG, Watkins PJ, Thomas PK, Sharma AK, Payan J (1983) The natural history of acute painful neuropathy in diabetes mellitus. J Neurol Neurosurg Psychiatry 26: 491-499

5. Tesfaye S, Malik R, Harris N, Jakubowski J, Mody C, Ward JD (1993) Painful and severe autonomic neuropathy following insulin: further evidence for microvascular disease in neuropathy. Diabetes 42: 196A (Abstract)

6. Tomlinson DR (1992) The pharmacology of diabetic neuropathy. Diabetes Metab Rev 8: 67-84

7. Harati Y (1987) Diabetic peripheral neuropathies. Annals Inter Med 107: 546-559

8. Young RJ (1993) Structural functional interactions in the natural history of diabetic polyneuropathy: a key to the understanding of neuropathic pain? Diabetic Med 10 [Suppl 2]: 89S-90S

9. Vinik AI, Holland MT, Le Beau JM, Liuzzi FJ, Stansberry KB, Colen LB (1992) Diabetic neuropathies. Diabetes Care 15: 1926-1975

10. The Diabetes Control and Complications Trial Research Group (1993) The effect of intensive treatment of diabetes on the development and progression of long-term complications in insulin dependent diabetes mellitus. $\mathrm{N}$ Engl J Med 329: 977-986

11. Tesfaye S, Stevens L, Stephenson J, Ward JD on behalf of the EURODIAB IDDM Study Group (1993) The prevalence of diabetic neuropathy and its relation to glycaemic control in insulin dependent subjects in Europe. Diabetologia 36 [Suppl 1]: A176 (Abstract)

12. Pirart J (1978) Diabetes mellitus and its degenerative complications: a prospective study of 4400 patients observed between 1947 and 1973. Diabetes Care 1: 168-188 and $252-263$

13. Ward JD, Barnes CG, Fisher DJ, Jessop JD, Baker RWR (1971) Improvement in nerve conduction following treatment in newly diagnosed diabetics. Lancet I: 428-430

14. Boulton AJM, Drury J, Clarke B, Ward JD (1982) Continuous subcutaneous insulin infusion in the management of painful diabetic neuropathy. Diabetes Care 5: 386-390

15. Fedele D, Bellavere F, Cardone C, Ferri M, Crepaldi G (1985) Improvement of cardiovascular autonomic reflexes after amelioration of metabolic control in insulindependent diabetic subjects with severe autonomic neuropathy. Horm Metabol Res 17: 410-413

16. Ziegler D, Mayer P, Muhlen H, Gries FA (1991) The natural history of somatosensory and autonomic nerve dysfunction in relation to glycaemic control during the first 5 years after diagnosis of type 1 (insulin-dependent) diabetes mellitus. Diabetologia 34: $822-829$

17. Pryce TD (1893) On diabetic neuritis with a clinical and pathological description of three cases of diabetic pseudo-tabes. Brain 16: 416-424

18. Woltman HW, Wilder RM (1929) Diabetes mellitus pathological changes in the spinal cord and peripheral nerves. Arch Intern Med 44: 576-603

19. Fagerberg SE (1959) Diabetic neuropathy: a clinical and histological study on the significance of vascular affections. Acta Med Scand 164 [Suppl 345]: 5-81
20. Bischoff A (1980) Morphology of diabetic neuropathy. Horm Metab Res 9 [Suppl]: 18-28

21. Brownlee M, Cerami A, Vlassara H (1988) Advanced glycosylation end products in tissue and the biochemical basis of diabetic complications. N Engl J Med 318: 1315-1321

22. Malik RA, Veves A, Masson EA et al. (1992) Endoneurial capillary abnormalities in mild human diabetic neuropathy. J Neurol Neurosurg Psychiatry 55: 557-561

23. Powell HC, Rosoff J, Myers RR (1985) Microangiopathy in human diabetic neuropathy. Acta Neuropathol (Berl) 68: 295-305

24. Yasuda H, Dyck PJ (1987) Abnormalities of endoneurial micro vessels and sural nerve pathology in diabetic neuropathy. Neurology 37: 20-28

25. Malik RA, Newrick PG, Sharma AK et al. (1989) Microangiography in human diabetic neuropathy: relationship between capillary abnormalities and the severity of neuropathy. Diabetologia 32: 92-102

26. Britland ST, Young RJ, Sharma AK, Clarke BF (1990) Relationship of endoneurial capillary abnormalities to type and severity of diabetic polyneuropathy. Diabetes 39: 909-913

27. Malik RA, Tesfaye S, Thompson SD et al. (1993) Endoneurial localisation of microvascular damage in human diabetic neuropathy. Diabetologia 36: 454-459

28. Timperly WR, Ward JD, Preston FE, Duckworth T, O'Malley BC (1976) Clinical and histological studies in diabetic neuropathy. Diabetologia 12: 237-243

29. Williams E, Timperly WR, Ward JD, Duckworth T (1980) Electronmicroscopical studies of vessels in diabetic peripheral neuropathy. J Clin Pathol 33: 462-470

30. Timperly WR, Boulton AJM, Davies Jones GAB, Jarrat JA, Ward JD (1985) Small vessel disease in progressive diabetic neuropathy associated with good metabolic control. J Clin Pathol 38: 1030-1038

31. Dyck PJ, Hansen S, Karnes J et al. (1985) Capillary number and percentage closed in human diabetic sural nerve. Proc Nat Acad Sci (USA) 82: 2513-2517

32. Malik RA, Tesfaye S, Thompson SD et al. (1994) Transperineurial capillary abnormalities in the sural nerve of patients with diabetic neuropathy. Microvascular Res [In Press]

33. Ford I, Malik RA, Newrick PG, Preston FE, Ward JD, Greaves M (1992) Relationship between haemostatic factors and capillary morphology in human diabetic neuropathy. Thromb Haemost 68: 628-633

34. Newrick PG, Wilson AJ, Jakubowski J, Boulton AJM, Ward JD (1986) Sural nerve oxygen tension in diabetes. BMJ 293: 1053-1054

35. Johnson PC, Doll SC, Cromey DW (1986) Pathogenesis of diabetic neuropathy. Ann Neurol 19: 450-457

36. Beggs J, Johnson PC, Olafsen A, Watkins CL, Cleary C (1991) Transperineurial arterioles in human sural nerve. J Neuropathol Exp Neurol 6: 704-718

37. Dyck PJ, Karnes JL, O'Brien P, Okazaki H, Lias A, Engelstad J (1986) The spatial distribution of fibre loss in diabetic polyneuropathy suggests ischaemia. Ann Neurol 19: 440-449

38. Dyck PJ, Lais A, Karnes JL, O’Brien P, Rizza R (1986) Fibre loss is primary and multifocal in sural nerves in diabetic polyneuropathy. Ann Neurol 19: 425-439

39. Asbury AK, Aldredge H, Hershberg R, Fisher CM (1970) Oculomotor palsy in diabetes mellitus: a clinico-pathological study. Brain 93: 555-566

40. Raff MC, Sangalang V, Asbury AK (1968) Ischaemic mononeuropathy multiplex associated with diabetes mellitus. Arch Neurol 18: 487-499 
41. Korthals JK, Gieron MA, Dyck PJ (1988) Intima of epineurial arterioles is increased in diabetic polyneuropathy. Neurology 38: 1582-1586

42. Roberts JT (1948) The effect of occlusive arterial disease of the extremities of the blood supply of nerves: experimental and clinical studies on the vasa nervorum. Am Heart J 35: 369-392

43. Korthals JK, Wisniewski HM (1975) Peripheral ischaemia. I. Experimental model. J Neurol Sci 24: 65-76

44. Nukada H, Dyck PJ (1984) Microsphere embolization of nerve capillaries and fibre degeneration. Am J Pathol 115: 275-287

45. Benstead TJ, Sangalang VE, Dyck PJ (1990) Acute endothelial swelling is induced in endoneurial microvessels by ischaemia. J Neurol Sci 99: 37-49

46. Tuck RR, Schmelzer JD, Low PA (1984) Endoneurial blood flow and oxygen tension in the sciatic nerves of rats with experimental diabetic neuropathy. Brain 107: 935-950

47. Cameron NE, Cotter MA, Low PA (1991) Nerve blood flow in early experimental diabetes in rats: relation to conduction deficits. Am J Physiol 261: E1-E8

48. Cameron NE, Cotter MA, Ferguson K, Robertson S, Radcliffe MA (1991) Effects of chronic alpha-adrenergic receptor blockade on peripheral nerve conduction, hypoxic resistance, polyols, $\mathrm{Na}+\mathrm{K}+$-ATPase activity and vascular supply in STZ-D rats. Diabetes 40: 16521658

49. Cameron NE, Cotter MA, Robertson S (1992) Angiotensin converting enzyme inhibition prevents the developments of muscle and nerve dysfunction and stimulates angiogenesis in streptozotocin-diabetic rats. Diabetologia 35: $12-18$

50. Low PA, Tuck RR, Dyck PJ, Schmelzer JD, Yao JK (1984) Prevention of some electrophysiologic and biochemical abnormalities with oxygen supplementation in experimental diabetic neuropathy. Proc Natl Acad Sci USA 81: 6894-6898

51. Low PA, Schmelzer JD, Ward KK, Curran GL, Poduslo JF (1988) Effect of hyperbaric oxygenation on normal and chronic streptozotocin diabetic peripheral nerves. Exp Neurol 99: 201-212

52. Low PA, Schmelzer JD, Ward KK, Yao JK (1986) Experimental chronic hypoxic neuropathy: relevance to diabetic neuropathy. Am J Physiol 250: E94-E99

53. Benstead TJ, Dyck PJ, Low P (1988) Chronic hypoxia induces selective maldevelopment of peripheral myelin in rat. J Neuropathol Exp Neurol 47: 599-608

54. Smith WJ, Diemel LT, Leach RM, Tomlinson DR (1991) Central hypoxaemia in rats provokes neurological defects similar to those seen in experimental diabetes mellitus: evidence for a partial role of endoneurial hypoxia in diabetic neuropathy. Neuroscience 45: 255-259

55. Stevens EJ, Lockett MJ, Carrington AL, Tomlinson DR (1993) Essential fatty acid treatment prevents nerve ischaemia and associated conduction anomalies in rats with experimental diabetes mellitus. Diabetologia 36: 397-401

56. Yasuda H, Sonobe M, Yamashita M et al. (1989) Effect of prostaglandin E1 analogue TFC 612 on diabetic neuropathy in streptozotocin-induced diabetic rats: comparison with aldose reductase inhibitor ONO 2235. Diabetes 38: $832-838$

57. Stevens EJ, Carrington AL, Tomlinson DR (1994) Nerve ischaemia in diabetic rats: time-course of development, effect of insulin treatment plus comparison of streptozotocin and BB models. Diabetologia 37: 43-48
58. Pugliese G, Tilton RG, Williamson JR (1991) Glucose-induced metabolic imbalances in the pathogenesis of diabetic vascular disease. Diabetes Metab Rev 7: 35-59

59. Williamson JR, Chang K, Allison W, Kilo C (1993) Endoneurial blood flow changes in diabetic rats. Diabetic Med 10 [Suppl 2]: 49S-51S

60. Monafo WW, Eliasson SV, Shimazaki S, Sugimoto $H$ (1988) Regional blood flow in resting and stimulated sciatic nerve of diabetic rats. Exp Neurol 99: 607-614

61. Boulton AJM, Scarpello JHB, Ward JD (1982) Venous oxygenation in the diabetic neuropathic foot: evidence of arterio-venous shunting? Diabetologia 22: 6-8

62. Tesfaye S, Harris N, Jakubowski J et al. (1993) Impaired blood flow and arterio-venous shunting in human diabetic neuropathy: a novel technique of nerve photography and fluorescein angiography. Diabetologia 36: 1266-1274

63. Llewelyn JG, Thomas PK, Fonseca V, King RHM, Dandona P (1986) Acute painful diabetic neuropathy precipitated by strict glycaemic control. Acta Neuropathol (Berl) 72: 157-163

64. Ward JD, Simms JM, Knight G, Boulton AJM, Sandler DA (1983) Venous distension in the diabetic neuropathic foot (physical sign of arterio-venous shunting). J Roy Soc Med 76: 1011-1014

65. Edmonds ME, Roberts VC, Watkins PJ (1982) Blood flow in the diabetic neuropathic foot. Diabetologia 22 : 9-15

66. Van-den-Hoogen F, Brawn LA, Sherriff S, Watson N, Ward JD (1986) Arteriovenous shunting in quadriplegia. Paraplegia 25: 282-286

67. Tesfaye S, Harris N, Wilson RM, Ward JD (1992) Exercise induced conduction velocity increment: a marker of impaired nerve blood flow in diabetic neuropathy. Diabetologia 35: 155-159

68. Greaves M, Preston FE (1984) Haemostatic abnormalities in diabetes. In: Jarrett RJ (ed) Metabolic aspects of cardiovascular disease 2. Diabetes and heart disease. Oxford: Elsevier, pp 47-80

69. O'Mally BC, Timperly WR, Ward JD, Porter NR, Preston FE (1975) Platelet abnormalities in diabetic neuropathy. Lancet II: 1274-1276

70. McMillan DE, Utterback NG, La Puma J (1978) Reduced erythrocyte deformability in diabetes. Diabetes 27: 895-901

71. Wautier J-L, Paton RC, Wautier MP et al. (1981) Increased adhesion of erythrocytes to endothelial cells in diabetes mellitus and its relation to vascular complications. N Eng J Med 305: 237-242

72. Baba Y, Kai M, Kamanda T, Setoyama S, Otsugi S (1979) Higher levels of erythrocyte membrane microviscosity in diabetes. Diabetes 28: 1138-1140

73. McMillan DE (1982) Further observations in serum viscosity change in diabetes mellitus. Metabolism 31: 274278

74. Steiness IB (1961) Influence of diabetic status on VP during ischaemia. Acta Med Scad 170: 319

75. Newrick PG, Boulton AJM, Ward JD (1987) Nerve ischaemia resistance: an early abnormality in diabetes. Diabetic Med 4: 517-520

76. Low PA, Ward KK, Schmelzer JD et al. (1985) Relationship of resistance to ischaemic conduction failure to energy metabolism in experimental diabetic neuropathy. Am J Physiol 248: E457-E462

77. Masson EA, Church SE, Woodcock AA, Hanley SP, Boulton AJM (1988) Is resistance to ischaemic conduction failure induced by hypoxia? Diabetologia 31: 762765 
78. Appenzeller O, Dhital KK, Cowen T, Burnstock G (1984) The nerve to blood vessels supplying blood to nerves: the innervation of the vasa nervorum. Brain Research 304: 383-386

79. Malik RA, Masson EA, Sharma AK et al. (1990) Hypoxic neuropathy: relevance to human diabetic neuropathy. Diabetologia 33: 311-318

80. Stoebner P, Mezin P, Vila A, Grosse R, Kopp N, Paramelle B (1989) Microangiopathy of endoneurial vessels in hypoxemic chronic obstructive pulmonary disease. Acta Neuropathol 78: 388-395

81. Robertson S, Cameron NE, Cotter NA (1992) The effect of calcium antagonist nifedipine on peripheral nerve function in streptozotocin-diabetic rats. Diabetologia 35: 1113-1117

82. Hotta N, Kakuta H, Fakasawa H et al. (1992) Effect of niceritrol on streptozotocin-induced diabetic neuropathy in rats. Diabetes 41: 587-591

83. Maxfield EK, Cameron NE, Cotter MA, Dines KC (1993) Angiotensin II receptor blockade improves nerve function, modulates nerve blood flow and stimulates endoneurial angiogenesis in streptotocin-diabetic rats. Diabetologia 36: 1230-1237

84. Low PA, Kihara M, Cameron N, Cotter J, Poduslo J (1993) Cause and effect of ischaemia in chronic experimental diabetic neuropathy. Diabetic Med 10 [Suppl 2]: 52S-55S

85. Bravenboer B, Kappelle AC, Hamers FPT, van Buren T, Erkelens DW, Gispen WH (1992) Potential use of glutathione for the prevention and treatment of diabetic neuropathy in the streptozotocin-induced diabetic rat. Diabetologia 35: 813-817

86. Low PA, Nickander KK (1991) Oxygen free radical effects in sciatic nerve in experimental diabetes. Diabetes 40: $873-877$

87. Cameron NE, Cotter MA, Archibald V, Dines KC, Maxfield EK (1994) Anti-oxidant and pro-oxidant effects on nerve conduction velocity, endoneurial blood flow and oxygen tension in non-diabetic and streptozotocin-diabetic rats. Diabetologia 37: 449-459

88. Jamal GA, Carmichael H (1990) The effect of gammalinolenic acid on human diabetic peripheral neuropathy: a double-blind placebo-controlled trial. Diabetic Med 7: 319-323

89. Cameron NE, Cotter MA, Robertson S (1991) Essential fatty acid diet supplementation: effects on peripheral nerve and skeletal muscle function and capillarization in streptozotocin-induced diabetic rats. Diabetes 40: 532539

90. Reja A, Tesfaye S, Harris N, Ward JD (1993) Improvement in nerve conduction and quantitative sensory tests after treatment with lisinopril. Diabetic Med 10 [Suppl 3]: S18 (Abstract)
91. Young MJ, Veves A, Walker MG, Boulton AJM (1992) Correlations between nerve function and tissue oxygenation in diabetic patients: further clues to the aetiology of diabetic neuropathy? Diabetologia 35: 1146-1150

92. Baynes JW (1991) Role of oxidative stress in the development of complications in diabetes. Diabetes 40: 405-412

93. Corbett JA, Tilton RG, Chang K et al. (1992) Aminoguanidine, a novel inhibitor of nitric oxide formation, prevents diabetic vascular dysfunction. Diabetes 41: 552-556

94. McVeigh GE, Brennan GM, Johnston GD et al. (1992) Impaired endothelium-dependent and independent vasodilation in patients with type 2 (non-insulin-dependent) diabetes mellitus. Diabetologia 35: 771-776

95. Tooke JE (1986) Microvascular haemodynamics in diabetes mellitus. Clin Sci 70: 119-125

96. Gabbay KH, Merola LO, Field RA (1966) Sorbitol pathway: presence in nerve and cord with substrate accumulation in diabetes. Science 151: 209-210

97. Ward JD, Baker RWR, Davis B (1972) Effect of blood sugar control on the accumulation of sorbitol and fructose in nervous tissue. Diabetes 21: 1173-1178

98. Dyck PJ, Zimmerman BR, Todd HV et al. (1988) Nerve glucose, fructose, sorbitol, myo-inositol and fibre degeneration and regeneration in diabetic neuropathy. N Engl J Med 319: 542-548

99. Greene D, Lattimer SA, Sima AAF (1987) Sorbitol, phosphoinositides, and sodium-potassium-ATPase in the pathogenesis of diabetic complications. N Engl J Med 316: 599-606

100. Greene D, Lattimer SA (1983) Impaired rat sciatic nerve sodium-potassium-ATPase in acute streptozotocin diabetes and its correction by dietary myo-inositol supplementation. J Clin Invest 72: 1058-1063

101. Das PK, Bray GM, Aguayo AJ, Rasminisky M (1976) Diminished ouabain-sensitive, sodium-potassium-ATPase activity in sciatic nerves of rats with streptozotocin-induced diabetes. Exp Neurol 53: 285-288

102. Spritz N, Marinan B, Singh H (1974) Effects of insulin on the incorporation of 14-Cleucine into the protein components of sciatic nerve myelin. Diabetes 23: 358

103. Sidenius P, Jakobson J (1987) Axonal transport in human and experimental diabetes. In: Dyck PJ, Thomas PK, Asbury AK, Winegrad AI, Porte D (eds). Diabetic neuropathy. Philadelphia: WB Saunders 260-265

104. Ishii DN (1993) Insulin and related neurotrophic factors in diabetic neuropathy. Diabetic Med 10 [Suppl 2]: 14S$15 \mathrm{~S}$

105. Schmidt RE (1993) The role of nerve growth factor in the pathogenesis and therapy of diabetic neuropathy. Diabetic Med 10 [Suppl 2]: 10S-13S 